УДК 911.9(470.57)

ПРИРОДНО-РЕСУРСНЫЙ ПОТЕНЦИАЛ РЕСПУБЛИКИ

БАШКОРТОСТАН: ОЦЕНКА, ТЕНДЕНЦИИ, ПРОБЛЕМЫ

\author{
Сафиуллин М.Р.
}

Институт стратегических исследований Республики Башкортостан, Уфа, e-mail: Marek1987@yandex.ru

В статье анализируется изменение роли и значения природно-ресурсного потенциала территорий на современном этапе рыночного социально-экономического развития России. Обосновывается объективная необходимость в условиях развивающихся рыночных отношений в переосмыслении стратегического значения и роли минерально-сырьевых ресурсов в социально-экономическом развитии территорий. Изменение роли природно-ресурсного потенциала территорий определяют следующие основные тенденции пространственного развития Российской Федерации: концентрация экономического роста в ограниченном числе центров, рост социально-экономической роли городов и в первую очередь городских агломераций; стабилизация численности населения в большинстве субъектов страны; сокращение межрегиональных социально-экономических диспропорций; трансформация пространственной организации экономики; усиление влияния научно-технического прогресса на пространственное развитие России. Рассмотрены затратная, экономическая, результативная концепции оценки природно-ресурсного потенциала территорий. Обоснована необходимость использования и научно-практическое значение рыночной оценки природно-ресурсного потенциала территорий. Предложена методика рыночной оценки природно-ресурсного потенциала территорий. Выполнена рыночная оценка минерально-сырьевых ресурсов (нефтяных, газовых, угольных рудных), лесных, водных и земельных ресурсов Республики Башкортостан. Исчерпание природно-ресурсного потенциала промышленного значения Республики Башкортостан к началу процесса инновационного развития страны объективно вынуждает пересмотреть содержание и идеологию концепций и альтернативных программ социально-экономического развития республики. Этап нефтяного развития Республики Башкортостан неотвратимо приближается к своему логическому завершению. На основе территориальной оценка природно-ресурсного потенциала Республики Башкортостан выделены инвестиционно-привлекательные зоны для развития определенных видов экономической деятельности. Сделаны выводы о роли и проблемах использования природно-ресурсного потенциала Республики Башкортостан в стратегическом социальноэкономическом развитии.

Ключевые слова: Республика Башкортостан, природно-ресурсный потенциал, методы оценки, рыночная оценка, тенденции, проблемы

\title{
NATURAL RESOURCE POTENTIAL OF THE REPUBLIC OF BASHKORTOSTAN: ASSESSMENT, TRENDS, PROBLEMS
}

\section{Safiullin M.R.}

\author{
Institute of Strategic Studies Republic of Bashkortostan, Ufa, e-mail: Marek1987@yandex.ru
}

The article analyzes the changing role and importance of natural resource potential of territories at the present stage of market socio-economic development of Russia. The article substantiates the objective necessity in the conditions of developing market relations in rethinking the strategic importance and role of mineral resources in the socio-economic development of territories. Changing the role of natural resource potential of the territories determine the following main trends of spatial development of the Russian Federation: the concentration of economic growth in a limited number of centers, the growth of socio-economic role of cities and especially urban agglomerations; stabilization of population in most subjects of the country; reduction of interregional socio-economic imbalances; transformation of the spatial organization of the economy; strengthening the impact of scientific and technological progress on the spatial development of Russia. The article considers the cost, economic, effective concept of assessing the natural resource potential of the territories. The necessity of use and scientific and practical value of market estimation of natural resource potential of territories is proved. The technique of market estimation of natural resource potential of territories is offered. The market evaluation of mineral resources (oil, gas, coal ore), forest, water and land resources of the Republic of Bashkortostan was carried out. Exhaustion of natural resource potential of industrial significance of the Republic of Bashkortostan to the beginning of the process of innovative development of the country objectively forces to reconsider the content and ideology of concepts and alternative programs of socio-economic development of the Republic. The stage of oil development of the Republic of Bashkortostan is inevitably approaching its logical conclusion. Based on the territorial assessment of the natural resource potential of the Republic of Bashkortostan, investment and attractive zones for the development of certain types of economic activity are identified. Conclusions are drawn about the role and problems of using the natural resource potential of the Republic of Bashkortostan in the strategic socio-economic development.

Keywords: Republic of Bashkortostan, natural resource potential, evaluation methods, market evaluation, trends, problems

Факторы «первой природы» (богатство природными ресурсами, благоприятные природные условия, выгодное географическое положение) мало зависят от чело- века. Опора развития территорий только на ресурсные преимущества замедляет модернизацию [1]. Наоборот, такие факторы «второй природы», как агломерационный 
эффект, формирующийся за счет высокой плотности населения и экономической деятельности, человеческий капитал (образование, здоровье, трудовые мотивации, высокий уровень доходов), институциональная среда (благоприятный предпринимательский климат, территориальная мобильность населения, стимулирование инноваций), развитие инфраструктуры, играют ключевую роль в территориально-структурной модернизации социоэкономики. Модернизация социоэкономики территорий быстрее идет там, где лучше условия для диффузии инноваций - выше концентрация населения и его качество, более развита инфраструктура и меньше экономическое расстояние, ниже институциональные барьеры.

В условиях развивающихся рыночных отношений возникает потребность в переосмыслении стратегического значения и роли минерально-сырьевых ресурсов при оценке социально-экономического потенциала субъектов в теоретическом и прикладном аспектах. Составляющие природно-ресурсного потенциала территории [2-4]:

1. Экономико-географическое положение региона - важная характеристика, определяющая меру соседства, проницаемость границ, доступность для внешних субъектов хозяйственных отношений и функциональные составляющие (транспортно-географическое, демографическое и другие виды положений).

2. Природные условия - среда, в пределах которой осуществляется функционирование всех региональных общественных подсистем (населения и расселения, социальные, экологические, экономические).

3. Природнье ресурсы - важнейшая составляющая интегрального потенциала региона.

В современной ситуации в экономике России, характеризующейся усилением роли территориальных факторов социально-экономического развития и в связи с принятием «Стратегии пространственного развития Российской Федерации на период до 2025 года», все большую научно-практическую значимость приобретает экономическая оценка природно-ресурсного потенциала субъектов страны [5].

Развитие процесса исчерпания невозобновляемых природных ресурсов и необходимость учета потребности в них в целях обеспечения их эффективного и рационального использования определяет необходимость рыночной стоимостной оценки природно-ресурсного потенциала территорий.
В работе дается рыночная оценка природных ресурсов, являющихся важнейшей составляющей природно-ресурсного потенциала Республики Башкортостан.

\section{Материалы и методы исследования}

В широком понимании природно-ресурсный потенциал территории - эта та часть природных ресурсов, которая может быть использована в хозяйственной деятельности при данных технических и социально-экономических возможностях при обеспечении устойчивого развития. В более узком экономическом понимании природно-ресурсный потенциал - это совокупность природных ресурсов и условий, явлений и процессов, которая, с одной стороны, является территориальной и ресурсной базой жизнедеятельности общества, а с другой, выступает как объект антропогенного воздействия общества.

Вплоть до 1960-х гг. в нашей стране была распространена концепция бесплатности природных ресурсов, так как они не являются продуктом трудовой деятельности человека. На рубеже 1970-х гг. наметилось исчерпание наиболее удобно расположенных месторождений полезных ископаемых, разработка которых позволяла получать дешевое, качественное сырье. Это повлекло за собой разработку новой концепции оценки природно-ресурсного потенциала - «затратной».

Экономическая стоимостная оценка определялась на основе затрат на освоение peсурса. Однако на практике часто общественно необходимая продукция подменялась любой (даже ненужной) продукцией, что приводило к затовариванию складов предприятий, магазинов и т.д.

Согласно «результативной» концепции, экономическая оценка ресурса определялась исходя из стоимости получаемой продукции или прибыли с единицы ресурса. Несмотря на недостатки этих концепций, они способствовали развитию теории экономической оценки природных ресурсов.

Нами предлагается использовать рыночный метод оценки природно-ресурсного потенциала территорий. В связи с тем, что в рыночной экономике России осложняющим фактором экономической оценки природных ресурсов стал инфляционный процесс, предлагается проводить стоимостную оценку природных ресурсов в международных валютах (доллар, евро) с учетом складывающихся цен на глобальных сырьевых рынках. Информационной 
базой при выполнении рыночной оценки природно-ресурсного потенциала Республики Башкортостан (РБ) послужили материалы Государственного доклада «О состоянии природных ресурсов и окружающей среды Республики Башкортостан в 2018 г.» Министерства природопользования и экологии РБ [6].

\section{Результаты исследования и их обсуждение}

Минерально-сырьевые ресурсы Башкирии явились первоисточником развития экономики, фактором, определившим формирование структуры производств в территориальных промышленных системах на основе разработки наиболее экономически выгодных природных ресурсов.

Для современной экономики регионов требуется динамичная рыночная оценка природно-ресурсного потенциала. Исчерпание природно-ресурсного потенциала промышленного значения Башкирии к началу процесса инновационного развития страны объективно вынуждает пересмотреть содержание и идеологию концепций и альтернативных программ социально-экономического развития республики. Этап нефтяного развития Республики Башкортостан неотвратимо приближается к своему логическому завершению. Нефти в республике осталось на 25-30 лет. В связи с этим экономику республики необходимо трансформировать в инновационном направлении: определить приоритеты стратегического территориально-структурного развития, источники формирования бюджетов и инвестиций, модернизировать систему подготовки кадров, содержание инновационного развития. И при этом должно обеспечиваться реальное повышение доходов и уровня жизни населения.
Рыночная стоимостная оценка природно-ресурсного потенциала РБ. Суммарный доход от всех нынешних извлекаемых нефтяных ресурсов при цене 60 долл. за баррель равен около 80 млрд долл., или 4800 млрд руб., что составляет сегодня всего три годовых ВРП республики (таблица).

Годовой объем добычи природного газа около 0,4 млрд $\mathbf{m}^{3}$. Ежегодная потребность экономики и населения республики в природном газе составляет 16 млрд м $^{3}$ Сегодняшняя стоимость извлекаемых запасов газа республики при цене в 250 долл. за 1 тыс. м $^{3}$ составляет 1 млрд долл., или 65 млрд руб.

Стоимостная ценность извлекаемых разведанных запасов угля республики оценивается всего в 2,1 млрд долл. или 130 млрд руб. Однако угли Южноуральского и Камского бассейнов РБ низкокачественные, неконкурентоспособные и «выпадают» из реальной рыночной экономики ввиду их невостребованности.

Медно-колчеданные руды. В 1970-е гг. добыча руд достигала 10 млн т. В 2008 г. около 3 млн т, в том числе Учалинский ГОК - 2,1 млн т, Башкирский медно-серный комбинат и Бурибайский рудник - 0,9 млн т. Извлекаемая ценность полезных компонентов разведанных запасов медноколчеданных руд оценивается в 22 млрд долл. Однако на РБ приходится только третья часть этой ценности, т.е. примерно 7 млрд долл., или 455 млрд руб. Остальной доход остается на медеплавильных и цинковых заводах Челябинской области.

Железная руда. Если добыть все извлекаемые запасы железной руды в республике, то можно получить доход в размере 0,5 млрд долл., или 32 млрд руб. С 2002 г. добыча и переработка железной руды в Башкирии прекращена из-за экономической неконкурентоспособности.

Современная рыночная цена природных ресурсов Республики Башкортостан

\begin{tabular}{|l|c|c|c|}
\hline \multirow{2}{*}{ Наименование ресурса } & \multicolumn{2}{|c|}{ Рыночная цена используемых ресурсов } & Доля ресурса \\
\cline { 2 - 4 } & Млрд долл. & Млрд руб. (в ценах 2017 г.) & $\%$ \\
\hline Земельные ресурсы & 1100 & 74000 & 90,5 \\
\hline Нефть & 80,0 & 4800 & 5.9 \\
\hline Водные ресурсы (за год) & 36,0 & 2300 & 2,8 \\
\hline Медно-колчеданные руды & 7,0 & 455 & 0,6 \\
\hline Природный и попутный газ & 1,0 & 65 & 0,08 \\
\hline Уголь & - & - & - \\
\hline Лесные ресурсы & 1,6 & 100 & 0.12 \\
\hline Итого: & 1225,6 & 81720 & 100,0 \\
\hline ВРП (2017) & 22 & 1396 & - \\
\hline
\end{tabular}


Лесныле ресурсы. Общий запас древесины оценивается в 765-830 млн м³. Доступные запасы для эксплуатации - 540 млн м². При расчетной лесосеке в 10 млн м³, в 1990 г. было заготовлено 5,4 млн м³ го 3,3 млн м³. Доход от использования доступных к разработке запасов древесины при нынешних ценах за $1 \mathrm{~m}^{3}$ круглой древесины в 3 долл. оценивается в 1,6 млрд долл., или около 100 млрд руб.

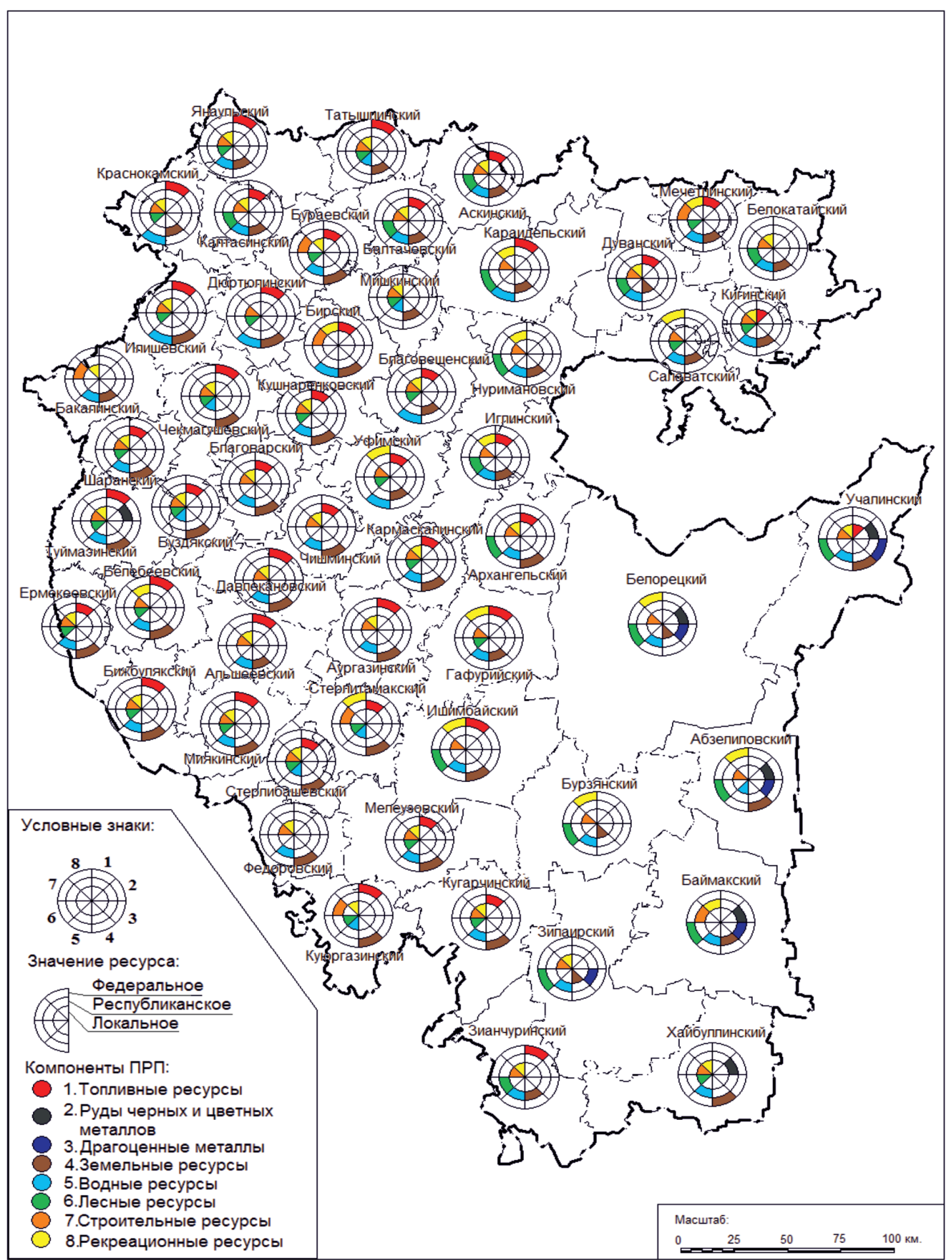

Природно-ресурсный потенциал районов Республики Башкортостан [7, с. 13] 
Земельные ресурсы. Сельскохозяйственные угодья республики составляют 7,4 млн га. По этому ресурсу идет процесс формирования рыночной цены с учетом спроса и предложения. Средняя рыночная цена 1 га земли достигает 10 млн руб. или 150 тыс. долл. Исходя из этого, цена всех сельхозугодий по средней рыночной цене составляет 74 трлн руб., или 1,1 трлн долл.

Boдные pecypcы. Объем суммарных запасов поверхностных вод, формирующихся на территории республики с учетом вод, поступающих из соседних областей и Республики Татарстан, и подземных вод, достигает 41,0 км$^{3}$. Исходя из современного уровня цен за водопотребление и водоотведение $1 \mathrm{~m}^{3}$ воды населением городов (56 руб. 27 коп.), рыночная цена всех водных ресурсов определяется в 2,3 трлн руб., или до 36 млрд долл.

На основе территориальной оценки природно-ресурсного потенциала Республики Башкортостан можно выделить следующие инвестиционно-привлекательные зоны для развития определенных видов экономической деятельности (рисунок):

1. Восточная (Горная), Южная и ЮгоВосточная часть Башкирии - рудно-лесохозяйственная зона.

2. Западная, Центральная и Юго-Западная часть Башкирии - индустриально-аграрная зона, развившаяся на основе использования нефтяных ресурсов и черноземных почв.

3. Северо-Западная часть - индустриальная зона, имеющая выгодное экономико-географическое положение, ресурсную базу (земельные, нефтяные, водные: реки Кама и Белая, а также Нижнекамское водохранилище).

Северная и Северо-Восточная часть аграрная зона. Отсутствуют эффективные природные ресурсы, кроме земельных

Современные проблемы использования природно-ресурсного потенциала РБ:

1. Основная часть доходов от использования индустриальных ресурсов (нефтяных, рудных и пр.) не достается самим территориям (районам и городам), а «оседает» в федеральном и региональном центре.

2. Экологические платежи за загрязнение природной среды не стимулируют повышение эффективности экономики природопользования ввиду мизерности платежей.

3. Финансовая и экологическая «закрытость» хозяйственной деятельности федеральных, частных, иностранных фирм и производств на территории муниципальных образований.
4. В сохраняющейся энергозатратной, энергоемкой и низкоэффективной экономике Башкирии с каждым годом нарастает дефицит дешевых и эффективных топливноэнергетических ресурсов.

5. Стратегию пространственного социально-экономического развития Башкирии необходимо разрабатывать исходя из перспектив падения роли природных ресурсов.

\section{Выводы}

Таким образом, из числа главных и эффективных природных ресурсов в республике остались только земельные и водные ресурсы. Свыше 95\% потребностей хозяйства и населения республики обеспечивается за счет импорта природного газа (до 16 млрд м $^{3}$ в год). В перспективе дефицит природного газа придется в возрастающих размерах компенсировать за счет импорта из Западной Сибири, Восточной Сибири и Казахстана. Для населения республики это обернется дальнейшим ростом цен на электроэнергию, газ, городской и автомобильный транспорт, услуги ЖКХ, продовольствие. Поэтому в стратегии территориального социально-экономического развития республики оценка роли влияния природно-ресурсного потенциала должна пересматриваться исходя из складывающихся и ожидаемых рыночных реалий цены природных ресурсов.

\section{Список литературы / References}

1. Доклад Всемирного банка о мировом развитии 2009. Новый взгляд на экономическую географию // Ред. А.А. Бандаренко, Е.И. Журавлева, О.А. Зимарин, Т.В. Кирсанова. М.: Весь Мир, 2009. 384 с.

World Bank world development report 2009. A new look at economic geography // Red. A.A. Bandarenko, E.I. Zhuravleva, O.A. Zimarin, T.V. Kirsanova. M.: Ves' Mir, 2009. 384 p. (in Russian).

2. Географическое положение и территориальные структуры: памяти И.М. Маергойза / сост.: П.М. Полян, А.И. Трейвиш. М.: Новый хронограф, 2012. 896 с.

Geographical position and territorial structures: in memory of I.M. Maergoiz / sost.: P.M. Polyan, A.I. Treyvish. M.: Novyy khronograf, 2012. 896 p. (in Russian).

3. Гладкевич Г.И. Природные условия и обеспеченность ресурсами // Россия: социально-экономическая география. М.: Новый хронограф, 2013. С. 44-92.

Gladkevich G.I. Natural conditions and availability of resources // Russia: socio-economic geography. M.: Novyy khronograf, 2013. P. 44-92 (in Russian).

4. Экономическая и социальная география России. География отраслей народного хозяйства / Под ред. В.Л. Бабурина, М.П. Ратановой. М.: Книжный дом «Либроком», 2013. $516 \mathrm{c}$.

Economic and social geography of Russia. Geography of branches of the national economy / Pod red. V.L. Baburina, M.P. Ratanovoy. M.: Knizhnyy dom «Librokom», 2013. 516 c. (in Russian).

5. Стратегия пространственного развития Российской Федерации на период до 2025 года. Распоряжение Прави- 
тельства РФ от 13 февраля 2019 г. № 207-р. [Электронный pecypc]. URL: https:/www.garant.ru/products/ipo/prime/ doc/72074066/ (дата обращения: 12.12.2019).

Spatial development strategy of the Russian Federation for the period up to 2025. Russian Government order No. 207-R of 13 February 2019. [Electronic resource]. URL: https://www. garant.ru/products/ipo/prime/doc/72074066/ (date of access 12.12.2019) (in Russian)

6. Государственный доклад «О состоянии природных ресурсов и окружающей среды Республики Башкортостан в 2018 г.». Министерство природопользования и экологии Республики Башкортостан. Уфа, 2019. 329 с.
State report «on the state of natural resources and environment of the Republic of Bashkortostan in 2018». Ministry of nature management and ecology of the Republic of Bashkortostan. Ufa, 2019. 329 p. (in Russian)

7. Ахунов А.Р. Экономико-географическая оценка территориальной организации хозяйства и населения с использованием бизнес-карт (на примере Республики Башкортостан): автореф. .... канд. геогр. наук. Пермь, 2010. 24 с.

Akhunov A.R. Economic and geographical assessment of the territorial organization of the economy and population using business cards (for example, the Republic of Bashkortostan): avtoref. ... kand. geogr. nauk. Perm', 2010. 24 p. (in Russian). 